\title{
Kastelugeeli rypsin kylvön apuna
}

\author{
Erkki Aura
}

MTT, maaperä ja ympäristö, 31600 Jokioinen, erkki.aura@mtt.fi

Ongelmat kylvön onnistumisessa ovat yleensä savi- ja hiesumailla paljon suuremmat kuin hieta- tai multamailla. Erityisesti pienisiemenisten kaksisirkkaisten kasvien, kuten rypsin, viljelyssä kevättöiden onnistumisen riski on suuri. Kuivumisvaaran vuoksi maa on muokattava hienoksi pienisiemenisille kasveille. Tällöin kuitenkin kasvaa maan liettymisvaara. Hydrofiiliset lankamaiset maan rakennetta stabiloivat orgaaniset polymeerit ovat luonnossa yleisiä. Eräs tapa vähentää muokkausalustan kuivumisesta tai kuorettumisesta aiheutuvia haittoja on keinotekoisten vahvasti vettä sitovien polymeerien käyttö siemenen itämisen ja taimettumisen varmentajina. MTT:llä Jokoisissa on muutamana vuotena kokeiltu kastelugeeliä rypsin kylvön apuna. Polymeeriksi valittiin lievästi hapan polyakryyliamidi (K504, Kemira). Käyttömäärä oli kenttäkokeissa 1 -1,5 kg/ha. Polymeeri liuotettiin veteen 0,7 prosenttiseksi geeliksi. Osmometrillä mitattuna saatiin vedelle noin 1,3 baarin osmoottinen arvo. Kylvön aikana pumpataan säiliöstä geeli ensin paksua silikoniletkua pitkin mäntäkalvopumpulla jakotukkiin, josta geeli jaetaan liittimien kautta kylvövantaiden sisässä oleviin paineletkuihin. Ajossa geeli laskeutuu kylvövaon pohjalle ja siemenet tippuvat geelin päälle. Geelinauhan tarkoituksena on: 1 . Luoda hyvä kontakti siemeneen ja luovuttaa nopeasti siemenelle itämiseen tarvittava vesi. 2. Koska geelissä lähes kaikki vesi on sidottuna makromolekyyleihin, niin geelin tehtävänä on myös hidastaa veden kapillaarista nousua maan pintaan päin ja näin säästää vettä siemenelle. 3. Geelin tarkoituksena on stabiloida maan rakennetta siemenen ympärillä, mikä vähentää märkänä alkukesänä liettymisen vaaraa. Geelitekniikkaa testattiin vuosina 2003 - 2005 kenttäkokeiden avulla. Vuonna 2003 oli alustava koe, jossa seitsemässä kylvössä yksinkertaisesti geeliä syötettiin vain toiseen puoliskoon kylvökonetta, ja verrattiin rypsin kehittymistä kylvökoneen puoliskojen välillä. Vuosina 2004 ja 2005 tehtiin molempina kesinä 2 kenttäkoetta, jossa kerranteiden lukumäärä oli neljä ja ruutujen sijainti oli satunnaistettu. Vuonna 2003 ensimmäistä kylvöä lukuunottamatta tulokseksi saatiin suurempi taimitiheys geelikylvöllä tavalliseen tekniikkaan verrattuna. Myös vuonna 2004 geelikylvö oli parantanut taimitiheyttä kummassakin kenttäkokeessa. Parantanut taimistuminen näkyi molempien kokeiden sadoissa. Vuoden 2005 laskentatulosten mukaan geelikylvöllä oli positiivinen vaikutus taimistumiseen, jos kylvö tehtiin 18.5, mutta toukokuun lopun kylvössä ei ollu juuri eroja kylvötekniikoiden välillä. Kesäkuun kylvössä geelillä on saattanut olla jopa negatiivinen vaikutus taimistumiseen. Sadoissa ei vuonna 2005 ollut kylvötekniikoiden välillä eroja. Silmähavainnot osoittivat, että geelikylvöllä ei voida poistaa hyvin karkean kylvöalustan haitallista vaikutusta rypsin itämiseen. Suurella ajonopeudella kylvökoneen vantaat värähtelevät voimakkaasti, mikä on voinut kokeissa pahasti katkoa kylvöalustan pohjaan laskeutuvaa geelinauhaa.

Asiasanat: rypsi, taimistuminen, geeli, tekniikka 


\section{Johdanto}

Kasvin siemenet tarvitsevat itääkseen riittävästi vettä, happea ja tavallisesti yli $5{ }^{\circ} \mathrm{C}$ lämpötilan. Vaikka siemen hyvin itäisi, maan pinnan kuorettuminen runsaan sateen jälkeen on vielä uhkana viljelyn onnistumiselle. Ongelmat kylvön onnistumisessa ovat yleensä savi- ja hiesumailla paljon suuremmat kuin hieta- tai multamailla. Erityisesti pienisiemenisten kaksisirkkaisten kasvien, kuten rypsin, viljelyssä kevättöiden onnistumisen riski on suuri. Koska näillä kasveilla siemenen ravintovarasto on suurikokoisiin siemeniin verrattuna pieni, on kylvö tehtävä matalaan, $2-4 \mathrm{~cm}: n$ syvyyteen. Kaksisirkkaiset kasvit eivät ole yhtä tehokkaita lävistämään kuorettunutta maata tai kiertämään kylvöalustan suuria kokkareita kuin yksisirkkaiset viljakasvit. Savimaan muokkaus karkeaksi aiheuttaa maan pinnan nopean kuivumisen, mikä alentaa matalaan kylvetyn siemenen vedensaantia. Karkeassa kylvöalustassa maan kosteus pintakerroksessa voi muutamassa tunnissa laskeutua alle lakastumisrajan (Heinonen 1985). Rypsillä, kuten sokerijuurikkaallakin, lakastumisrajaa (veden imu maassa 15 baaria) voidaan pitää raja-arvona siemenen itämiselle kuivassa maassa (Aura 1975, Rypsin viljelyvarmuuden parantaminen 2005). Kuivumisvaaran vuoksi maa on muokattava hienoksi pienisiemenisille kasveille. Tällöin kuitenkin kasvaa maan liettymisvaara. Liettyneessä maassa huokostila on täyttynyt vedellä runsaan sateen aikana. Hapen liikkuminen maan vesitilassa on 1/10000 osa hapen diffuusionopeudesta maan ilmatilassa. Kosteana keväänä rypsin siemen kärsii liettyneessä kylvöalustassa hapen puutetta ja pian sateen lakattua liettynyt maa alkaa muodostaa taimen pintaantuloa estävää kuorta.

Hydrofiiliset lankamaiset maan rakennetta stabiloivat orgaaniset polymeerit ovat luonnossa yleisiä (Greenland et.al. 1962). Niitä syntyy maassa bakteerien toiminnan tuloksena. Kasvin juurista erittyy limamaisia aineita. Lierot erittävät myös näitä liima-aineita. Luonnon polymeerit muistuttavat paljolti keinotekoisia liimoja. Nämä molekyylit sisältävät runsaasti karboksyyli-, amino- ja amidiryhmiä, joiden avulla liimayhdisteet tarttuvat tiukasti maan mineraaliainekseen: saveshiukkasiin ja alumiinija rautaoksideihin. Tähän perustuen lankamaiset molekyylit stabiloivat tehokkaasti maan mururakennetta. Lisäksi limamaiset aineet lisäävät kontaktia juuren ja maan kiinteän aineksen välillä parantaen näin ravinteiden ja veden saantia maasta.

Eräs tapa vähentää muokkausalustan kuivumisesta tai kuorettumisesta aiheutuvia haittoja on keinotekoisten vahvasti vettä sitovien polymeerien käyttö siemenen itämisen ja taimettumisen varmentajana. Maan vedensitomiskyvyn lisääjinä ja rakenteen stabiloijina on maailmalla tutkittu paljon lankamaisia polyakryyliamidiyhdisteitä, joissa amidi- ja trimetyyliammonium ryhmät sitovat polaarisia vesimolekyylejä ja tarttuvat myös maan kiinteään ainekseen stabiloiden tehokkaasti maan rakennetta (Barvenik 1994). Maan rakenteen parantajana polyakryyliamidi on erittäin tehokas, jo muutamalla kilolla hehtaarille voi olla huomattava vaikutus. Kasvimateriaaleista on kehittetty biopolymeerejä korvaamaan polyakryyliamidia, mutta eloperäisten polymeerien tehokkuus maan rakenteen stabiloijina on jäänyt heikommaksi kuin polyakryyliamidin (Orts et. al. 2000).

MTT:llä Jokoisissa on muutamana vuotena tutkittu kastelugeeliä rypsin kylvön apuna. Aluksi kokeiltiin polyakryylipohjaisten ns. kastelukiteiden käyttöä. Kastelukiteissä lankamaisten polyakryylimolekyylien välille on lisätty poikittaisia sidoksia, jolloin polymeeri ei enää ole geelimuodossa, vaan toimii kiinteinä paloina, joiden vedensitomiskyky on erittäin suuri, jopa tuhansia prosentteja kuivan kiteen painosta. Taloudellisista syistä polymeerejä voidaan käyttää hehtaaria kohden vain muutama kilo. Pienen kidemäärän annostelu ja sijoittaminen rypsin siemenen lähelle osoittautui teknisesti vaikeaksi. Sen sijaan geelimäisen polyakryyliamidin sijoittamiseen kylvöalustaan siemenen alapuolelle riitti yksinkertaisempi tekniikka.

\section{Kehitetty tekniikka ja tavoitteet}

Polymeeriksi valittiin lievästi hapan polyakryyliamidi (K504, Kemira). Käyttömäärä oli kenttäkokeissa 1 -1,5 kg/ha. Polymeeri liuotettiin veteen 0,7 prosenttiseksi geeliksi. Osmometrillä mitattuna saatiin vedelle noin 1,3 baarin osmoottinen arvo. Korkeampaa pitoisuutta ei voitu käyttää, 
koska jo yhden prosentin seoksessa viskositeetti oli liian korkea levitettäväksi pumpun ja letkujen avulla kylvöalustaan siemenen alle. Tutkimuksessa oli kaksi osaa: 1. Sopivan tekniikan kehittäminen geelin annosteluun noin yhden cm:n levyiseksi nauhaksi siemenrivin alapuolelle kylvöalustaan. 2 . Geelin vaikutuksen selvittäminen kenttäkokeiden avulla savimaalla.

Tekniikan kehittämisessä päädyttiin käyttämään siemenvantaiden sisään pujotettuja puolen baarin paineletkuja, joiden sisäläpimitta on 2,5 mm. Säiliöstä geeli pumpataan ensin paksua silikoniletkua pitkin mäntäkalvopumpulla (Flojet) jakotukkiin, josta geeeli jaetaan liittimien kautta kylvövantaiden sisässä oleviin paineletkuihin. Lähelle vantaiden alapäätä on hitsattu pienet lyhyet teräsholkit, joiden kautta paineletkut pujotetaan. Paineletkujen päihin on kiinnitetty lyhyt pala silikoniletkua, joka estää maan tarttumisen letkuihin.Silikoniletkun pää ulottuu lähes vantaiden alareunaan saakka. Ajossa geeli laskeutuu kylvövaon pohjalle ja siemenet tippuvat geelin päälle.

Geelinauhan tarkoituksena on: 1. Luoda hyvä kontakti siemeneen ja luovuttaa nopeasti siemenelle itämiseen tarvittava vesi. 2. Koska geelissä lähes kaikki vesi on sidottuna makromolekyyleihin, niin geelin tehtävänä on myös hidastaa veden kapillaarista nousua maan pintaan päin ja näin säästää vettä siemenelle. 3. Geelin tarkoituksena on stabiloida maan rakennetta siemenen ympärillä, mikä vähentää märkänä alkukesänä liettymisen vaaraa. Geelitekniikkaa testattiin vuosina 2003 - 2005

kenttäkokeiden avulla. Vuonna 2003 oli alustava koe, jossa yksinkertaisesti geeliä syötettiin vain toiseen puoliskoon kylvökonetta, ja verrattiin rypsin kehittymistä kylvökoneen puoliskojen välillä. Vuosina 2004 ja 2005 tehtiin molempina kesinä 2 kenttäkoetta, jossa kerranteiden lukumäärä oli neljä ja ruutujen sijainti oli satunnaistettu.

\section{Tulokset ja tulosten tarkastelu}

Vuosina 2003 ja 2004 satoi hyvin runsaasti kylvöaikojen välillä ja maa oli kylvöalustassa varsin kosteaa. Keväällä 2005 sateet eivät haitanneet kevättöitä. Tulokset on esitetty kuvissa $1-5$. Vuonna 2003 laskettiin taimiston tiheys 6 eri aikaan suoritetusta kylvöstä. Ensimmäistä laskentaa lukuunottamatta tulokseksi saatiin suurempi taimitiheys geelikylvöllä tavalliseen tekniikkaan verrattuna. Myös vuonna 2004 kuvan 2 mukaan geelikylvö oli parantanut taimitiheyttä kummassakin kenttäkokeessa. Parantanut taimistuminen näkyi molempien kokeiden sadoissa, kun kylvö oli tehty 11.5. Vuoden 2005 laskentatulosten mukaan geelikylvöllä oli positiivinen vaikutus taimistumiseen, jos kylvö tehtiin 18.5, mutta toukokuun lopun kylvössä ei ollu juuri eroja kylvötekniikoiden välillä. Kesäkuun kylvössä geelillä on saattanut olla jopa negatiivinen vaikutus taimistumiseen. Sadoissa ei vuonna 2005 ollut kylvötekniikoiden välillä eroja. Vuosi 2005 oli rypsille edullinen kesä. Tämä seikka on voinut tasoittaa vaikutukset eri koejäsenten välillä. Silmähavainnot osoittivat, että geelikylvöllä ei voida poistaa hyvin karkean kylvöalustan haitallista vaikutusta rypsin itämiseen. Myös koemaiden kosteutta seurattiin keväisin. Tulosten tarkempi analysointi on vielä kesken. Vuonna 2003 ajettiin kylvössä traktorilla hitaasti, noin 5 km/h. Muina vuosina ajonopeus oli noin $10 \mathrm{~km} / \mathrm{h}$. Suuremmalla ajonopeudella kylvökoneen vantaat värähtelivät voimakkaasti, mikä on voinut pahasti katkoa kylvöalustan pohjaan laskeutuvaa geelinauhaa.

\section{Johtopäätökset}

Vuosina 2003 - 2005 tehdyissä kenttäkokeissa savimaalla geelitekniikalla on ollut positiivinenn vaikutus rypsin taimistumiseen. Tulokset ovat kuitenkin riippuneet sääoloista, kylvöajasta ja kylvöalustan karkeudesta. Mittaustuloksien analysointia on vielä tarkennettava. Myös konetekniikkaa on ilmeisesti parannettava, koska kehitetyssä systeemissä kylvövantaiden värinä saattaa pahasti katkoa kylvöalustan pohjaan laskeutuvaa geelinauhaa. Ainekustannus on pieni, korkeintaan muutama euro hehtaaria kohden. Kylvökoneen lisälaitteiden hinnaksi tulee noin 1000 euroa 
Kastelugeelin vaikutus rypsin taimettumiseen v. 2003

$\mathrm{kpl} / \mathrm{m}^{2}$

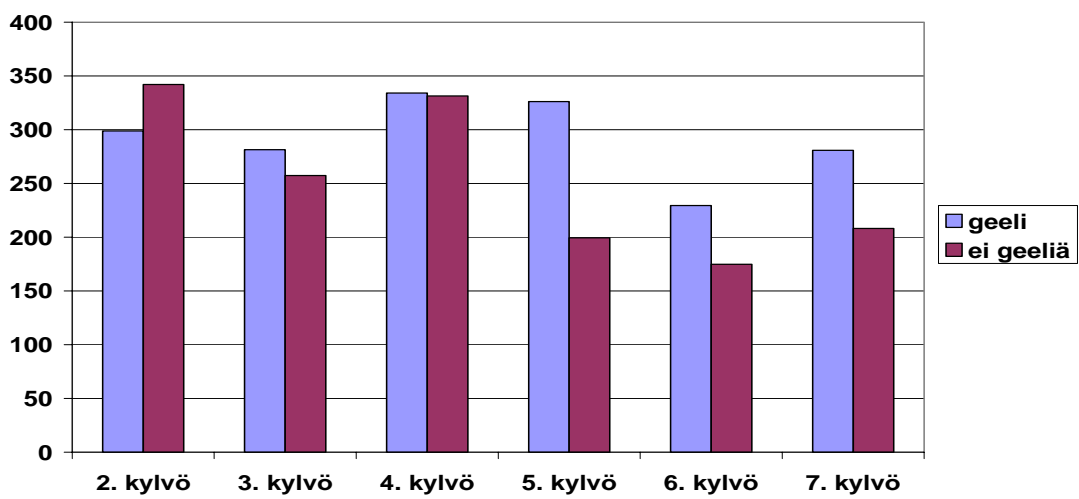

Kuva 1: Vuoden 2003 rypsin taimilaskennan tulokset.

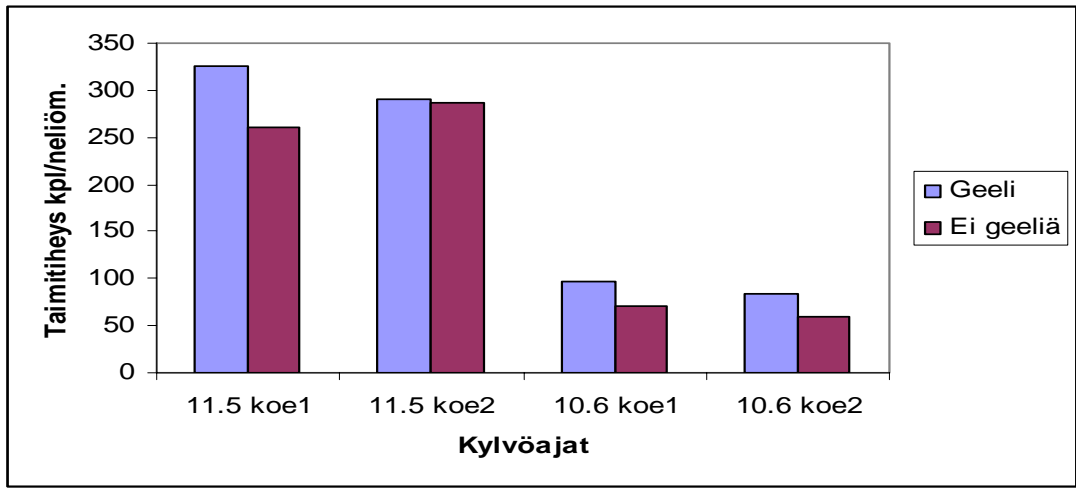

Kuva 2: Vuoden 2004 taimilaskennan tulokset kahdesta kahdesta kokeesta .

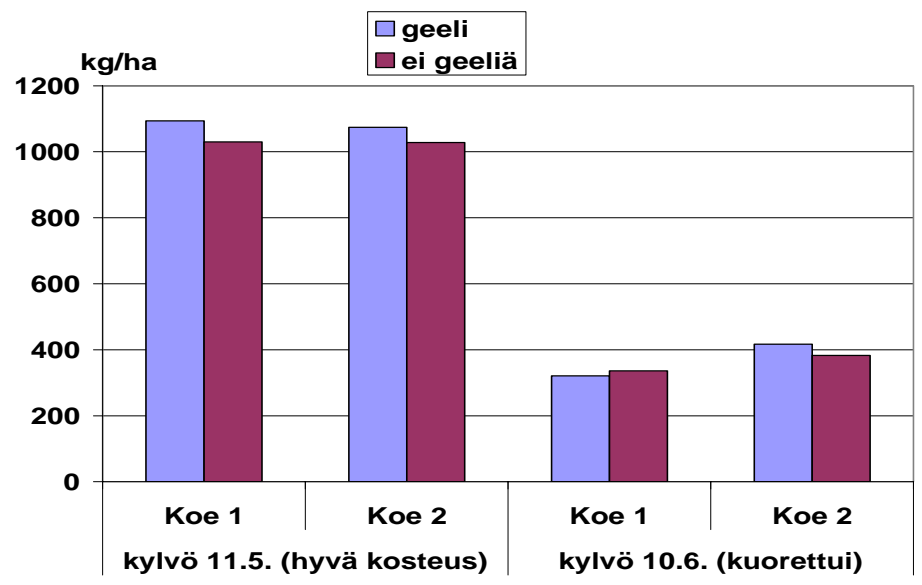

Kuva 3: Vuoden 2003 satotulokset. 

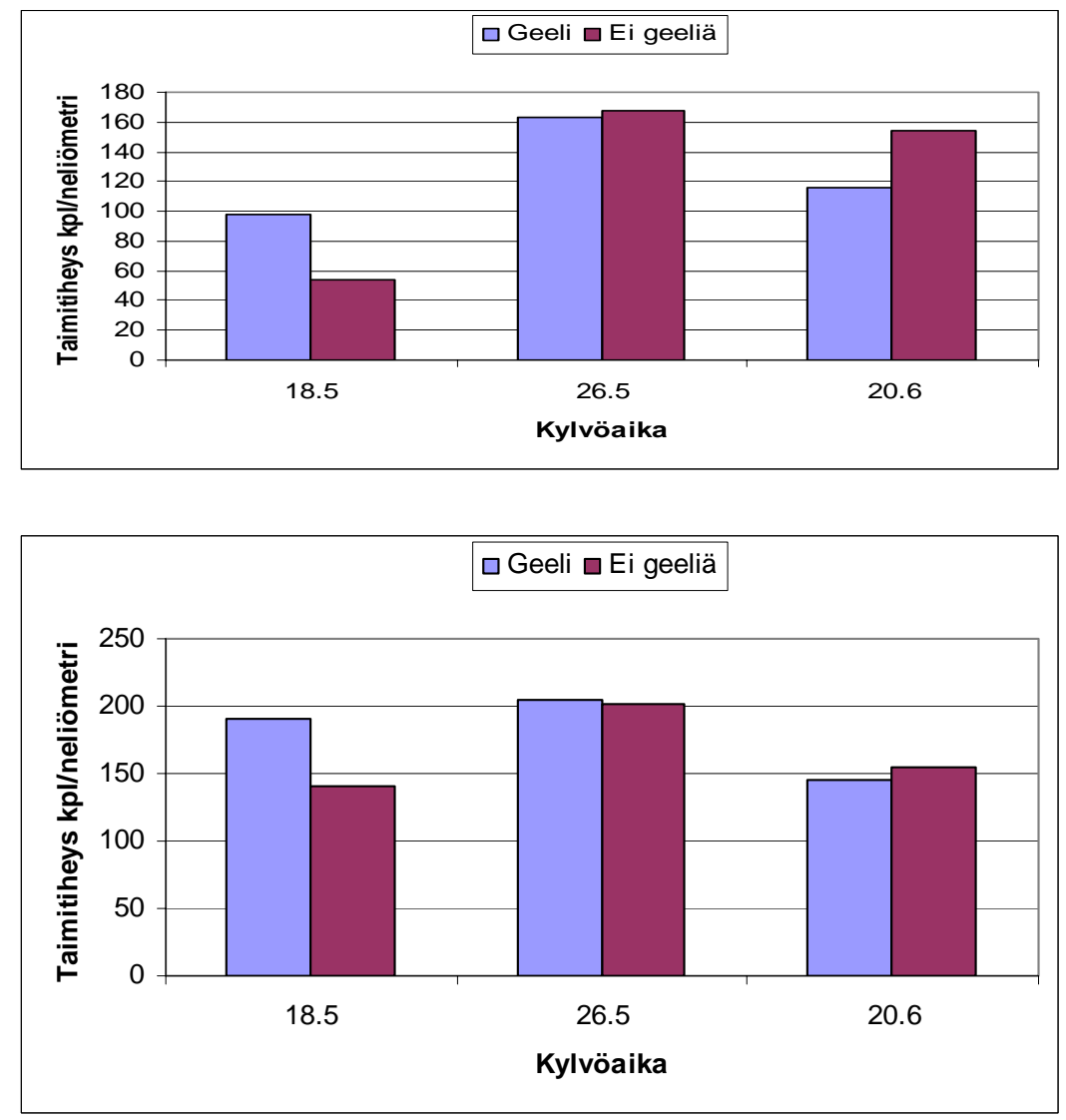

Kuvat 4 ja 5: Taimilaskennan tulokset kahdesta kokeesta vunna 2005.

\section{Kirjallisuus}

Aura, E. 1975. Effects of soil moisture on the germination and emergence of sugar beet (Beta vulgaris L.) J. Scient. Agric. Soc. Finland 47: 1-70.

Barvenik, F.W. 1994. Polyacrylamide characteristics related to soil applications. Soil Sci. 158: 235-243.

Greenland, D. J., Lindstrom, G. R. \& Quirk, J. P. 1962. Organic materials which stabilize natural soil aggregates. Soil Sci. Soc. Am. Proc. 26: 366-371.

Heinonen, R. Soil management and crop water supply. Department of Soil Sciences Swedish University of Agricultural Sciences, Sweden, 105 p. ISBN-91-576-0052-X.

Orts, W.J., Sojka, R.E. \& Glenn G. M. 2000. Biopolymer additives to reduce erosion-induced soil losses during irrigation. Industrial Crops and Products 11: 19-29.

Rypsin viljelyvarmuuden parantaminen. 2002-2004. Loppuraportti. Syyskuu 2005. 13 p. 